\title{
A construção da Linha Sul da Estrada de Ferro São Paulo - Rio Grande (1908-1910) mão de obra e migrações ${ }^{*}$
}

\section{The construction of the Southern Railway from São Paulo to Rio Grande (1908-1910) labor and migrations ${ }^{\star *}$}

\author{
MÁRCIA JANETE ESPIG \\ Professora do Mestrado em História \\ Universidade Federal de Pelotas (UFPel) \\ Rua Alberto Rosa, 154, Centro \\ CEP 96010-770 - Pelotas - RS \\ marcia.espig@terra.com.br
}

RESUMO Entre os anos de 1908 e 1910, a construção da Linha Sul da Estrada de Ferro São Paulo - Rio Grande (EFSPRG) movimentou a região que hoje corresponde ao meio oeste catarinense. $\mathrm{Na}$ época esta zona era disputada entre Paraná e Santa Catarina, e reconhecida como território contestado entre os estados. Os trabalhos de construção da ferrovia exigiram um grande esforço humano e financeiro, tendo envolvido milhares de trabalhadores. Os operários menos qualificados, responsáveis pelas tarefas mais pesadas e conhecidos como "turmeiros", formaram um contingente de cerca de 8 mil homens.

* Artigo recebido em: 19/04/2011. Aprovado em: 28/12/2012.

** Este artigo sintetiza algumas discussões realizadas em minha tese de doutoramento. ESPIG, Márcia Janete. Personagens do Contestado: os turmeiros da Estrada de Ferro São Paulo - Rio Grande (1908-1915). Porto Alegre, UFRGS, 2008. (História, Tese de doutorado). 
Durante minha pesquisa, a documentação apontou uma presença significativa de imigrantes entre estes trabalhadores. Muitos destes trabalhavam na construção apenas de forma sazonal. Nos períodos de entressafra nas colônias, migravam para a região da construção da ferrovia a fim de obter ganhos extras. Estas migrações teriam, inclusive, prejudicado o estabelecimento de algumas colônias no estado do Paraná, mas ainda não receberam a devida atenção da historiografia. Neste trabalho pretendo analisar com detalhe esta migração.

\section{Palavras-chave EFSPRG, turmeiros, migração}

Abstract: Between the years of 1908 and 1910, the construction of the Southern Railway from São Paulo to Rio Grande (EFSPRG) stimulated the region that nowadays corresponds to the Catarinense middle-west. At that time this area was disputed between Parana and Santa Catarina, and it was recognised as a contested territory between the states. The labor construction demanded a huge human and financial effort and involved thousands of workers. The least qualified members of staff were responsible for heavier tasks and they were known as "turmeiros", who constituted a contingent of about 8 thousand men. Throughout this research, the documentation indicated a significant presence of immigrants amongst these workers. Lots of them used to work in construction only as a seasonal mean. In periods of colonial intercropping, they migrated to the railway construction region aiming to obtain extra earnings. These migrations would have, inclusive, damaged the establishment of some colonies in the state of Parana, which have not received the due historiography attention yet. In this work, I intend to analyze in details this migration.

Keywords EFSPRG, turmeiros, migration

\section{Considerações iniciais}

A construção da linha Sul da Estrada de Ferro São Paulo - Rio Grande reuniu, em um espaço restrito e por um período relativamente curto, um grande contingente de mão de obra. Milhares de homens deslocaram-se para a região do vale do rio do Peixe, no meio oeste catarinense, a fim de trabalhar nas pesadas tarefas de abertura de caminhos, assentamento de trilhos, construção de "obras de arte"1 etc. Os operários que atuavam nos

1 As obras de arte são aquelas obras mais detalhadas e complexas em uma construção de estrada de ferro e, consequentemente, mais caras: "As obras d'arte, nas estradas de ferro, constam de boeiros, pontilhões, pontes, viaductos, passagens superiores, passagens inferiores, tunneis, galerias de abrigo contra-neve, contra a areia, etc.” PICANÇO, Francisco. Diccionario de estradas de ferro, sciencias e artes accessorias. Rio de Janeiro: H. Lombaerts \& Com., 1892, v.II, p.158-159. 
trabalhos mais pesados eram conhecidos como "turmeiros", já que eram divididos em turmas.

A busca de mão de obra foi um problema constante durante a construção da ferrovia, e a empresa responsável valeu-se de diferentes estratégias para sua obtenção, como mostrarei mais adiante. Neste artigo pretendo destacar sobretudo a presença de imigrantes estrangeiros entre estes trabalhadores, notadamente aqueles que, já estabelecidos em colônias, eram aliciados ou se retiravam no período de entressafra, atuando nas tarefas de construção. Pretendo demonstrar que este contingente não foi numericamente desprezível, e que sua saída deu-se de forma paulatina da região, permanecendo em pequeno número no vale do rio do Peixe.

Para o enfoque desta pesquisa, são muito importantes as apreciações teóricas da micro-história, pois a variação da escala de observação permitiu maior atenção ao detalhe. A micro-história busca relacionar formulações teóricas iniciais às informações trazidas por amplo material empírico. Neste sentido, a evidência documental possui preponderância frente à teoria, podendo inclusive contribuir para sua reformulação. ${ }^{2} \mathrm{~A}$ preocupação empírica relaciona-se ao talhe limitado do objeto micro-histórico: a investigação intensiva deve levar à busca do máximo possível de conhecimentos a ele referentes. Observe-se, portanto, a ambição de um aproveitamento máximo da riqueza dos acervos existentes, e um "estudo intensivo do material documental". ${ }^{3}$

O caráter experimental da micro-história está relacionado a outros aspectos metodológicos, tais como a elaboração e o teste de hipóteses. A disciplina histórica, lembra Revel, tem por objeto fatos não reproduzíveis. Entra em cena, portanto, a ousadia nas propostas e nos procedimentos que, no caso da micro-história,

consiste na criação de condições de observação que farão aparecer formas, organizações, objetos inéditos. Traduz-se, por um lado, por um recurso constante a condições assim definidas ao mesmo tempo, é claro, que as suas modificações posteriores durante a análise. ${ }^{4}$

Desta maneira, a observação será distinta ao nível microscópico, emergindo novas formas de investigação e temáticas pouco visíveis ao nível macro.

2 GINZBURG, Carlo. A história e a micro-história: uma entrevista com Carlo Ginzburg. Ouro Preto, $L P H$ - Revista de História, n.1, p.4, 1990.

3 LEVI, Giovanni. Sobre a micro-história. In: BURKE, Peter. (org.) A escrita da história: novas perspectivas. São Paulo: UNESP, 1992, p.136.

4 REVEL, Jacques. Prefácio. A história ao rés-do-chão. In: LEVI, Giovanni. Herança imaterial: trajetória de um exorcista no Piemonte do século XVII. Rio de Janeiro: Civilização Brasileira, 2000, p.20-21. 
Surge um espaço privilegiado para a especulação, com hipóteses e análises inovadoras.

A atenção ao detalhe mostrou-se uma ferramenta fundamental, alcançada através do recurso ao chamado paradigma indiciário. ${ }^{5}$ Os processos mentais a este relacionados recorrem a pequenos detalhes, migalhas que, somadas, apresentam uma realidade apenas perceptível aos mais atentos. Através deste paradigma, acredita Ginzburg, as ciências humanas e sobretudo a história poderão atingir pontos antes considerados inalcançáveis, através da investigação de sinais ou indícios. Como resultado, teremos uma flexibilização que acentua seu caráter experimental e o relaciona ao particular, ao não generalizável:

A orientação quantitativa e antiantropocêntrica colocou as ciências humanas num desagradável dilema: ou assumir um estatuto científico frágil para chegar a resultados relevantes, ou assumir um estatuto científico forte para chegar a resultados de pouca relevância. (...) Mas vem a dúvida de que este tipo de rigor é não só inatingível mas também indesejável para as formas de saber mais ligadas à experiência cotidiana (...). Em situações como essas, o rigor flexível (se nos for permitido o oxímoro) do paradigma indiciário mostra-se ineliminável. ${ }^{6}$

Tais orientações adequaram-se à dimensão reduzida de meu objeto de estudo, permitindo uma interessante aproximação analítica. Sem a variação de escala de análise e o uso intensivo de fontes, os turmeiros permaneceriam na invisibilidade historiográfica em que haviam caído, sobretudo pela dificuldade em obter documentação significativa sobre sua história.

\section{Os primórdios da EFSPRG}

Foi em seus momentos finais que o Império brasileiro aprovou um projeto há muito acalentado pelo poder público, assinando-se o decreto que autorizava a construção de um caminho de ferro que faria a ligação da província de São Paulo ao sul do Brasil. Em 9 de novembro de 1889, através do decreto n.10.432, o engenheiro João Teixeira Soares recebeu do Governo Imperial autorização para "construcção, uso e goso" da ferrovia que passou a ser denominada Estrada de Ferro São Paulo - Rio Grande (EFSPRG). No dia 14 de novembro Teixeira Soares assinou o contrato com o Governo Federal, e apenas seis dias após a assinatura do decreto e um dia após a assinatura do contrato, caía a Monarquia e com ela o compromisso entre as partes.

5 GINZBURG, Carlo. Sinais: raízes de um paradigma indiciário. In: Mitos, emblemas, sinais: morfologia e história. São Paulo: Companhia das Letras, 1989.

6 GINZBURG, Carlo. Sinais: raízes de um paradigma indiciário, p.178-179. 
O decreto n.10.432 estabelecia uma garantia de juros de $6 \%$ durante 30 anos sobre o capital necessário para a construção da linha principal, desde que não excedesse o máximo de 37.000:000\$000 (trinta e sete mil contos de réis); além disso, fazia cessão gratuita das terras devolutas que se encontravam ao longo das linhas, num total de $30 \mathrm{~km}$ para cada lado. Seguiam-se cinquenta cláusulas, relativas a diversos aspectos, tais como os direitos da concessão, especificações técnicas, detalhes da fiscalização, das tarifas a serem cobradas, etc. Havia grande preocupação em torno dos prazos concedidos a Teixeira Soares. A empresa deveria ser organizada no máximo em um ano (Cláusula II) e os trabalhos deveriam começar em no máximo sessenta dias após a aprovação dos estudos finais e ser concluídos no máximo em cinco anos (Cláusula IV). As obras não poderiam ser interrompidas; caso o fossem, caducariam os privilégios e as garantias (Cláusula XXXV). Muitos eram os deveres atribuídos à Companhia, inclusive o de transportar gratuitamente colonos e imigrantes, além de sementes e plantas enviadas a estes pelo governo, bem como malas do correio.

A questão da imigração recebeu destaque no Decreto Imperial. As Cláusulas 39 a 46 organizavam a colonização nas terras servidas por suas linhas férreas. A Companhia deveria estabelecer em terras a serem demarcadas até dez mil famílias de agricultores nacionais e estrangeiros, no prazo máximo de quinze anos. Cada família teria direito a um lote de terras de dez hectares e uma casa construída. Enquanto tivessem seu sustento provido pela Estrada de Ferro, os colonos trabalhariam 15 dias por mês em seus lotes e os demais dias para a Companhia, mediante um salário acordado entre as partes. As despesas feitas pela empresa com os colonos seriam cobradas em prestações anuais ou semestrais, com uma taxa de 5\% ao ano, concedendo-se um título provisório aos chefes de famílias que, com a quitação, seria substituído por um titulo definitivo. 0 governo estabelecia também que $15 \%$ das famílias poderiam ser nacionais; as outras seriam compostas de imigrantes europeus ou das possessões portuguesas e espanholas que chegassem ao país por conta própria ou por conta do governo. Neste sentido, colocava a Cláusula XLIV, o único compromisso do Governo seria o de encaminhar os imigrantes para as localidades, onde seriam recebidos pelos agentes dos contratantes. Na Cláusula XLVI destacava-se que cada família imigrante que possuísse ao menos três pessoas aptas para o trabalho agrícola valeria à Companhia uma subvenção governamental de 250\$ (duzentos e cinqüenta réis), e cada família nacional, 200\$ (duzentos réis). Completava a mesma Cláusula: 
O Governo pagará, além disso, as passagens dos trabalhadores que a Companhia importar até ao número de 3.000 para a execução das obras na fórma do contracto celebrado com Angelo Fiorita, Fonseca \& Cunha, e José Antunes dos Santos, em 4 de dezembro de $1888 .^{7}$

Por um lado, Teixeira Soares arcava com uma grande responsabilidade, visto que teria que empreender esforços além da própria construção da ferrovia, ao comprometer-se com a colonização de tão vasta região; por outro, assegurava a mão-de-obra cuja carência já havia constatado ao fazer estudos e explorações na região. O Relatório de Estudos da EFSPRG, dirigido por Teixeira Soares em 1889 ao Governo Imperial, já mencionava a dificuldade de obtenção de mão-de-obra na região que compreendia a chamada terceira seção, que ia do Rio Iguaçu (Porto da União) até o Rio Uruguai. Nesta zona, então pouco povoada, e que até poucos anos estava "entregue aos selvagens",

os salarios serão mais elevados porque os trabalhadores terão de ser obtidos de muito mais longe; os preços unitarios dos serviços serão mais altos do que nas outras secções por causa das difficuldades de transporte. Serão necessarias tres estações de $4^{\text {a }}$ classe e 28 casas de turma. ${ }^{8}$

Com a queda da Monarquia, contudo, foi necessário um novo decreto que tratasse da concessão desta ferrovia. 0 decreto republicano n.305, de 7 de abril de 1890, apresentou uma série de alterações. Neste, o Chefe do Governo Provisório declarava efetiva a concessão original feita a Teixeira Soares, modificadas porém algumas cláusulas. Na Cláusula I se estabelecia que o capital garantido seria de trinta contos de réis por $\mathrm{km}$ da referida estrada. A Cláusula III reduzia para $15 \mathrm{~km}$ de cada lado do eixo o limite da zona máxima de concessão de terrenos. Os prazos passaram a contar a partir da data de renovação do contrato, conforme publicação no Diário Oficial. Relativamente às cláusulas que tratavam da colonização dos terrenos próximos à via férrea, a Cláusula IV estabelecia que "ficam de nenhum effeito".

Porque o governo fez tal modificação? Talvez o Governo Provisório quisesse enfatizar o papel da EFSPRG como estrada estratégica, que possibilitaria rápido deslocamento de tropas ao sul do continente. Também podemos supor que a subvenção aos colonos, conforme prometida pelo Império, tenha soado como um gasto excessivo ao novo regime. Uma correspondência interna dos

7 PAIVA, Alberto Randolpho. Legislação Ferro-viaria Federal do Brazil: leis, decretos, regulamentos, instrucções, avisos, portarias e outros actos, desde as primeiras iniciativas até 31 de dezembro de 1921. Rio de Janeiro: s/ed, 1922, v.VI (1889-1890), p.331.

8 SOARES, João Teixeira. Relatório dos estudos da estrada de ferro de São Paulo: Rio Grande. Rio de Janeiro: Imprensa Nacional, 1889, p.13. 
A construção da Linha Sul da Estrada de Ferro São Paulo - Rio Grande (1908-1910): mão de obra e migrações

diretores da Brazil Railway Company, de 1907, agrega ainda outra informação: Teixeira Soares teria afirmado que as cláusulas de colonização foram eliminadas naquele momento por requerimento da Société Générale. ${ }^{9}$

Permaneceu, portanto, um dos problemas que se tornariam centrais na construção da EFSPRG: a carência de mão de obra considerada adequada para a dura tarefa de abertura de caminhos para a ferrovia. A noção do que seria "adequado" incluía preconceitos contra a mão-de-obra nacional e especialmente contra os trabalhadores do interior da região, os caboclos.

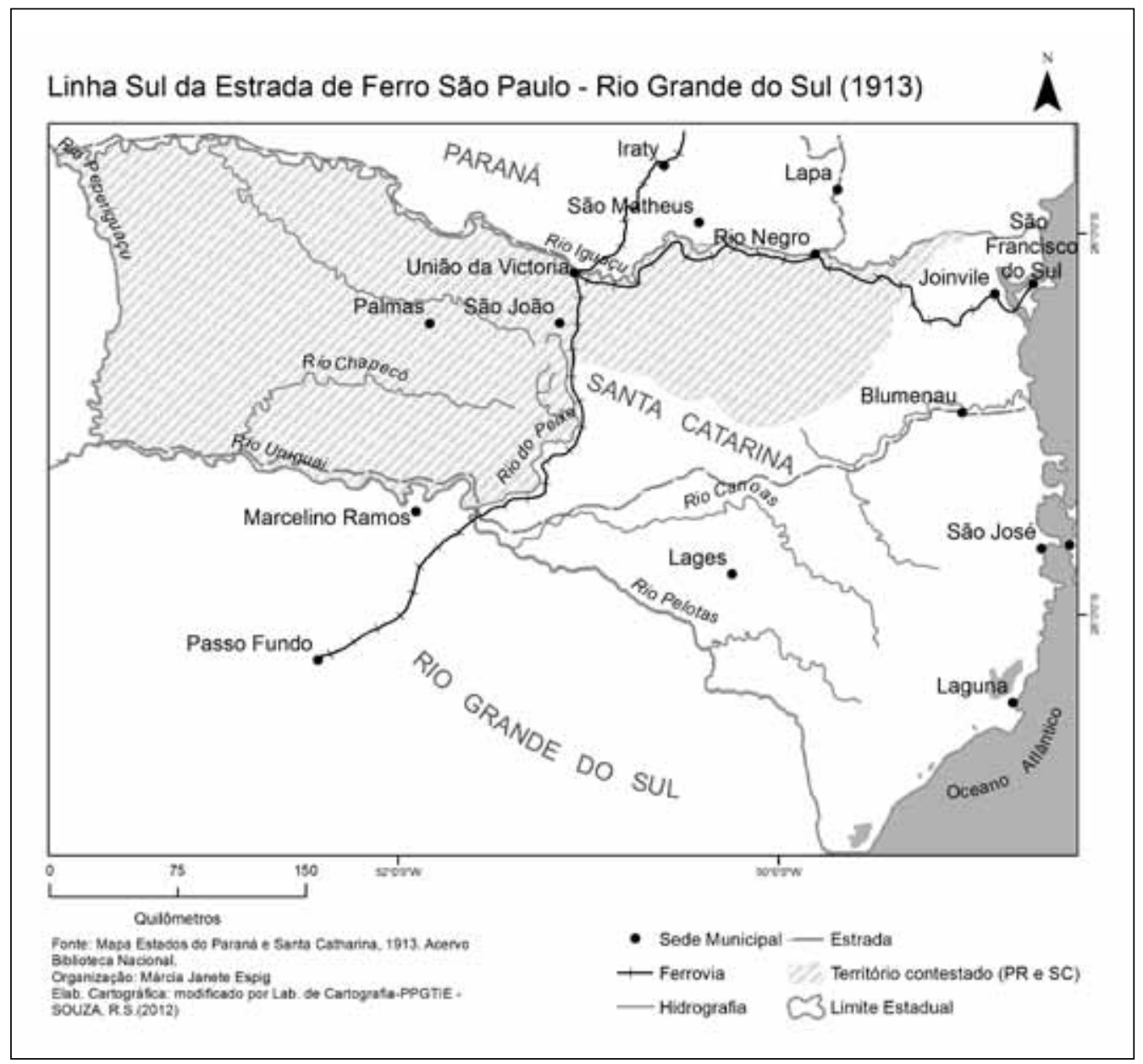

Detalhe dos Estados do Paraná e Santa Catharina, 1913, com indicação do trajeto da Linha Sul da EFSPRG.

9 MACKENZIE, Alexander. Correspondência a Percival Farquhar. Rio de Janeiro, 21 de agosto de 1907. (Arquivo Particular de Ana Lucia Duarte Lanna; original em inglês). A Societé Générale era uma das instituições financeiras européias junto às quais o empreendimento buscou investimentos. 


\section{As fases de construção da EFSPRG e as estratégias de obtenção de mão de obra}

A construção da EFSPRG foi, desde seu princípio, bastante peculiar, pois foi realizada a partir de várias frentes de trabalho. 0 trecho entre Santa Maria da Boca do Monte e Cruz Alta (que ficou a cargo da companhia Chemins de Fer Sud Oest Brésiliens), com $142 \mathrm{kms}$, foi concluído e inaugurado em novembro de 1894. A mesma companhia ficou responsável pelo trecho entre Cruz Alta e o Rio Uruguai. Assim, a tarefa da EFSPRG passava a ser (através de contrato de 1896) realizar a linha entre Itararé, em São Paulo, e as barrancas do Rio Uruguai, divisa entre Santa Catarina e Rio Grande do Sul. ${ }^{10}$ Os trabalhos de construção da linha principal foram realizados em dois sentidos, sendo a cidade de Ponta Grossa considerada como referência. Enquanto a Linha Norte partia para Itararé, a Linha Sul

teve como centro de partida a estação localizada em Ponta Grossa até Paulo Frontin e, desta estação, até a margem direita do rio Iguaçu, em União da Vitória; igualmente, além da margem esquerda do rio Iguaçu (Porto União), em demanda do Vale do Peixe, para atingir o rio Uruguai na localidade de Marcelino Ramos, no Rio Grande do Sul. ${ }^{11}$

O primeiro trecho, entre Ponta Grossa e Rebouças, ficou concluído em 1899; o trecho entre Ponta Grossa e União da Vitória foi inaugurado em 1905. No ano seguinte tiveram início as obras em direção ao norte, que foram concluídas em setembro de $1908 .{ }^{12}$ Contudo os trilhos já atingiam Jaguariaíva (Paraná) no início de 1906 e boa parte da Linha Norte se encontrava operacional. A Linha Sul voltou a ser atacada em 1906, embora oficialmente os serviços tenham iniciado em janeiro de 1907. No início deste ano, uma empresa holding ${ }^{13}$ norte americana, a Brazil Railway Company (BRC), concluiu o processo de aquisição das ações da EFSPRG e assumiu o controle da diretoria. No final de 1907 a Companhia conseguiu obter do governo uma prorrogação do prazo, estendido em três anos. Ou seja, até o final de 1910 a linha deveria estar completamente concluída. Em abril de 1908 a Linha Sul

10 THOMÉ, Nilson. Trem de ferro: história da ferrovia no Contestado. $2^{\mathrm{a}}$ ed. Florianópolis: Lunardelli, 1983 , p.54.

11 KROETZ, Lando. As estradas de ferro do Paraná (1880-1940). São Paulo, USP, 1985, p.77. (Economia, Tese de doutorado em História Econômica).

12 NODARI, Renato. Estrada de ferro São Paulo - Rio Grande: causas e conseqüências de sua construção em território catarinense - 1900/1940. Porto Alegre, UFRGS, 1999, p.84. (Economia, Dissertação de mestrado).

13 Por definição uma empresa holding controla outras empresas por meio de participação acionária. 
chegara à estação de São João, estando aberta ao tráfego. ${ }^{14}$ Em novembro daquele ano a BRC contratou o italiano Achiles Stenghel como engenheiro chefe dos trabalhos da Linha Sul.

Para vencer as inúmeras dificuldades da construção, Stenghel realizou um planejamento detalhado. No trecho entre São João e Marcelino Ramos, que possuía cerca de $315 \mathrm{~km}$ de extensão, organizou uma divisão minuciosa a fim de atacar concomitantemente diferentes partes da ferrovia. 0 percurso foi separado em cinco divisões, diretamente subordinadas ao Chefe da Construção, com os números de $3^{\mathrm{a}}, 6^{\mathrm{a}}, 7^{\mathrm{a}}, 8^{\mathrm{a}}$ e $9^{\mathrm{a}}$, dirigidas por engenheiros. Cada divisão, por sua vez, era dividida em quatro ou cinco residências, ocupadas por engenheiros residentes. ${ }^{15}$

Hierarquicamente abaixo dos engenheiros residentes (que estavam encarregados de todas as tarefas relacionadas à conservação da via permanente) ${ }^{16}$ encontravam-se os mestres de linha e os feitores. Estas categorias não possuíam formação especifica para as funções que desempenhavam, que compreendiam uma série de tarefas auxiliares aos engenheiros. Além destas figuras, conta-se ainda com outro importante personagem: o empreiteiro. A divisão de ferrovias em empreitadas era comum a várias construções e buscava trazer maior agilidade. Na construção da Linha Sul da EFSPRG, Aquiles Stenghel dividiu cada residência entre vários pequenos empreiteiros, chamados de "taifeiros", que recebiam da Companhia por empreitada. Estes homens recebiam os trabalhadores, já divididos em turmas numerosas, e se responsabilizavam pelo pagamento de seus salários. ${ }^{17}$ Os "taifeiros", também conhecidos como "tarefeiros", eram "Empreiteiros encarregados de comandar equipes de trabalho e que recebiam por tarefa concluída". ${ }^{18}$

Na mais baixa posição hierárquica do trabalho da construção de ferrovias encontrava-se o "turmeiro". Considerado um trabalhador desqualificado, era responsável pelas tarefas mais duras e pesadas, tais como a abertura de cami-

14 SILVA, Cleto da. Apontamentos históricos de União da Vitória, 1769-1933. União da Vitória: Ed. do Autor, 1933, p.93.

15 Jornal O Libertador, Campos Novos, 09/02/1910.

16 Via permanente: "Repartição da Estrada de Ferro em trafego, que abrange a linha ferrea, os edificios e a linha telegraphica". PICANÇO, Francisco. Diccionario de estradas de ferro, sciencias e artes accessorias, v.II, p.327; "O chamando serviço da via permanente compreendia a conservação, reparação, reconstrução e melhoramentos da linha, edifícios e suas dependências", p.328. Para maiores detalhes técnicos, consultar ainda PICANÇO, Francisco. Diccionario de estradas de ferro, sciencias e artes accessorias. Rio de Janeiro: H. Lombaerts \& Com., 1891. v.I.

17 THOMÉ, Nilson. Trem de ferro, p.88-89.

18 NODARI, Renato. Estrada de ferro São Paulo - Rio Grande, p.86. Sistema semelhante era utilizado, na mesma época, no outro grande empreendimento da BRC, a Estrada de Ferro Madeira - Mamoré. FERREIRA, Manoel Rodrigues. A ferrovia do diabo: história de uma estrada de ferro na Amazônia. São Paulo: Melhoramentos, 2005, p.218. 
nhos, deslocamento ou retirada de terra e pedras, assentamento de dormentes e trilhos etc. Frequentemente esta mão-de-obra era composta, nas ferrovias em geral, de trabalhadores itinerantes que se deslocavam pelo território nacional em busca de oportunidades. No mais das vezes movimentando-se de ferrovia para ferrovia, comumente não possuíam família a acompanhá-los. A dispensa em um caminho de ferro representava a migração para outro. É difícil avaliar o volume numérico deste contingente em território nacional. ${ }^{19}$

A despeito de todas as suas falhas, a construção da Linha Sul da EFSPRG foi uma obra monumental e envolveu um grande volume de mão-de-obra. Seu estudo aprofundado me faz pensar em uma divisão em três tempos ou fases, bem marcadas entre si. Primeiramente um momento de dificuldades, no qual a construção, por uma série de motivos, evoluiu muito lentamente. Esta fase vai de 1899 a 1908 , e envolve a construção de um trecho relativamente pequeno do tronco principal Sul. A segunda fase inicia-se com a nomeação de Stenghel para os trabalhos, que começam a evoluir de maneira surpreendentemente rápida. Este é o auge da construção, com a entrada em cena de milhares de turmeiros, e vai até janeiro de 1910. O terceiro momento é marcado pela diminuição progressiva do número de trabalhadores e sua retirada da região, e encerra-se com a chegada da linha às barrancas do Rio Uruguai e com a construção da ponte provisória sobre este (dezembro de 1910).

A documentação utilizada em meu estudo demonstrou, tanto para a primeira quanto para a segunda fase descritas acima, a existência de um grande esforço na captação de imigrantes europeus como mão de obra para a construção da Linha Sul da EFSPRG. Como esta estratégia não se mostrou suficiente, buscou-se atrair trabalhadores ociosos em território nacional, especialmente na região sul. Neste perfil, assinalaram-se várias situações de aliciamento de imigrantes em colônias durante períodos de sazonalidade dos produtos agrícolas, estabelecendo-se portanto uma situação de migração temporária destes trabalhadores. Responsáveis por uma migração interna específica e em geral relacionada às más colheitas ou à sazonalidade da produção, estes operários foram, ao que tudo indica, egressos principalmente de colônias agrícolas paranaenses.

Mencionei anteriormente algumas peculiaridades da construção da EFSPRG e da Linha Sul. Aquela vinha sendo construída em dois sentidos, norte e

19 No caso da Linha Sul da EFSPRG, a preocupação com a aglomeração humana proporcionada pela construção do caminho de ferro levou a empresa a criar uma organização paramilitar. O Corpo de Segurança da EFSPRG foi possivelmente criado por Aquiles Stenghel em finais de 1908 a fim de exercer um papel repressivo sobre turmeiros e taifeiros, embora as queixas de maus tratos sejam anteriores a sua criação. Posteriormente atuou como agente de retirada de posseiros das terras lindeiras à ferrovia, pertencentes à BRC. Após o final da construção da Linha Sul o Corpo de Segurança passou a servir diretamente à Companhia, muito provavelmente anexando-se à defesa das serrarias da BRC na região. 
sul. Até o ano de 1907, o andamento anual era pífio e nem de perto atendia ao ritmo esperado pelo Governo Federal. Neste período os trabalhos seguiram de forma bastante irregular. Muitos foram os motivos alegados pela empresa junto ao Governo, tais como a necessidade de uma revisão geral do traçado primitivo e as dificuldades da topografia da zona. Em dezembro de 1907 (portanto já sob controle da BRC) a Companhia celebrou com o Governo um acordo no qual se estipulava que as obras deveriam estar concluídas em 3 anos; além disso a fiscalização sobre os trabalhos e os gastos passaria a ser mais rigorosa. Logo após a assinatura do contrato, houve melhoras no andamento dos trabalhos no trecho sul, abrindo-se ao tráfego o trecho entre União da Vitória e São João.

0 ano de 1906 indicou uma retomada mais séria, por parte da empresa, da construção deste caminho de ferro. Não por acaso, este foi o período de aquisição da EFSPRG pela holding BRC. Contudo, em abril de 1908 o problema da escassez de mão de obra continuava crônico. O simples oferecimento de salários compensadores não parecia suficientemente atraente para que se atingisse o número necessário de turmeiros. Parte das dificuldades de obtenção de mão-de-obra devia-se à região em que a construção se desenvolvia, ao preconceito contra os habitantes locais e também à ampla oferta de ferrovias que se encontravam em construção. No final do ano de 1906 havia $3.042 \mathrm{~km}$ em obras no território nacional, além de $6.683 \mathrm{~km}$ com estudos aprovados, ou seja, prestes a iniciar os trabalhos. ${ }^{20}$ Uma das maiores concorrentes na busca de trabalhadores era justamente a outra grande obra da BRC, a Madeira-Mamoré. Lá as mortes e doenças se faziam tão freqüentes que tornavam necessário um constante recrutamento de homens saudáveis, e a Companhia acrescentou à contratação de brasileiros um grande volume de estrangeiros, sobretudo da América Central. ${ }^{21}$ Diferentemente da ferrovia ao Sul, contudo, não havia a intenção de utilizar esta imigração para a colonização ao longo da linha.

A nova direção assumiu a EFSPRG em 2 de janeiro de 1907. Em junho do mesmo ano foi assinado um importante decreto que, entre outras questões, recolocava a colonização dos terrenos marginais à ferrovia, condição similar a que continha a concessão de 1889 e que fôra expurgada em 1891:

20 MINISTERIO DA INDUSTRIA, VIAÇÃO E OBRAS PUBLICAS. Relatorio apresentado ao Presidente da Republica dos Estados Unidos do Brazil pelo Ministro de Estado dos Negocios da Industria, Viação e Obras Publicas, Miguel Calmon Du Pin e Almeida no anno de 1907. Rio de Janeiro: Imprensa Nacional, 1907, p.137.

21 "O contingente maior era procedente das Antilhas e Barbados. Vinham, em segundo lugar, os espanhóis. Depois, os brasileiros e portugueses, e, em menor número, gregos, italianos, franceses, hindus, húngaros, portugueses, dinamarqueses, enfim, de cada nacionalidade havia representantes na construção da estrada, uns em maior, outros em menor número". FERREIRA, Manoel Rodrigues. A ferrovia do diabo, p.211. 
Pela clausula VIII do decreto n. 6.533, de 20 de junho do anno findo, obrigou-se a companhia a promover a colonização das terras marginaes da estrada, o que, sem duvida, será um dos factores mais poderosos para o incremento desta importante via ferrea que atravessa, presentemente, vasta extensão de terras pouco povoadas e quasi incultas, comquanto disponham de riquezas naturaes de bom aproveitamento. ${ }^{22}$

Ao final de 1907, a Diretoria da BRC tinha em suas mãos três grandes problemas a resolver referentes à EFSPRG: a aceleração da construção da Linha Sul, a carência de mão-de-obra em seus serviços (agravada pelos ataques indígenas em novembro daquele ano) e o compromisso com a colonização da região, determinada pelo decreto n. 6. 533 e detalhada pelo acordo celebrado entre a Companhia e o Ministério em dezembro de 1907. Os três problemas, como se percebe facilmente, estavam relacionados, e a empresa lutou para solucioná-los conjuntamente e da forma menos onerosa possível.

\section{Os turmeiros da EFSPRG}

A chave do problema, sem dúvida, era a mão-de-obra. Algumas estratégias passaram a ser empregadas pela Companhia. Os salários oferecidos eram considerados atraentes para a época. Houve ainda o deslocamento de trabaIhadores responsáveis pela conservação da via permanente da ferrovia, motivo de desagrado do engenheiro fiscal. Outra estratégia utilizada, e que rendeu críticas à empresa, foi o desvio de turmeiros da construção do ramal São Francisco da EFSPRG para o tronco principal. Enquanto os trabalhos deste sofriam incremento, a construção da linha São Francisco foi se restringindo durante 1907, praticamente cessando. Mesmo assim, faltavam braços para o trabalho na Linha Sul. Entraram em jogo, portanto, alguns aliciadores de mão-de-obra, para a mão-de-obra regional, nacional e de regiões coloniais, e a importação de trabalhadores estrangeiros, tarefa mais complexa, sem dúvida, mas que facilitava a realização do objetivo seguinte da Companhia: a colonização dos terrenos contíguos à ferrovia.

Sobre os personagens que denominei aliciadores de mão-de-obra temos pouquíssimas referências. Um deles seria Batista Raphaeli, que recrutava homens na região serrana. Raphaeli recebeu algumas menções nos jornais da região. Temos relatos sobre sua ação em 1908, na primeira fase dos trabalhos de construção. ${ }^{23} \mathrm{Em}$ uma ocasião menciona-se o número de trabalhadores: Ra-

22 MINISTERIO DA INDUSTRIA, VIAÇÃO E OBRAS PUBLICAS. Relatorio apresentado ao Presidente da Republica dos Estados Unidos do Brazil pelo Ministro de Estado dos Negocios da Industria, Viação e Obras Publicas, Miguel Calmon Du Pin e Almeida no anno de 1908. Rio de Janeiro: Imprensa Nacional, 1908, p.983.

23 O Clarim, Lages, 08/01/1908; 19/02/1908; 12/06/1908. O Trabalho, Curitibanos, 18/08/1908. 
phaeli teria seguido de Lages para o Rio do Peixe com uns "sessenta e tantos" homens, ${ }^{24}$ o que me leva a acreditar que as turmas por ele reunidas deveriam possuir em torno deste número.

Localizei outra citação a estes aliciadores de trabalhadores nacionais em um periódico curitibano. O jornal refere-se ainda à "qualidade" destes homens, considerados extremamente desclassificados:

S P - R S. Nestes ultimos dias tem chegado a esta capital mais de 1.000 trabalhadores para a Estrada de Ferro São Paulo - Rio Grande, e hoje vieram mais de 300. Os contractantes, segundo parece, estão arrebanhando a escoria dos vagabundos do Rio, Santos e São Paulo, de sorte que esses individuos tem dado que fazer a policia para manter a ordem na hospedaria de immigrantes onde se teem alojado. Ainda ontem o Sr. Dr. Chefe de Policia esteve até ás 11 horas da noite na hospedaria, a fim de manter a ordem. 0 embarque hoje para Ponta Grossa desse pessoal, foi feito pela policia com um contingente de infantaria e um piquete de cavallaria. ${ }^{25}$

Chamo a atenção do leitor para o fato de que esta foi a única referência localizada em toda minha pesquisa sobre trabalhadores nacionais trazidos do sudeste para a construção da Linha Sul. Obviamente isso não significa a inexistência de outros grupos oriundos do centro do país; contudo as alusões mais corriqueiras a grandes grupos de homens trabalhadores dizem respeito a imigrantes estrangeiros, e não a nacionais. ${ }^{26}$ Esta afirmação é válida não apenas para os periódicos, mas também para outras fontes sobre o tema. Entrevistado por Monteiro, Benedito Chato, que trabalhou na construção, relatou que "Destes lados, (...) referindo-se à extremidade sul da ferrovia, não registrou a presença de trabalhadores vindos de outras partes do país". ${ }^{27}$

A necessidade da empresa em trazer braços válidos para a construção e, subseqüentemente, para a colonização da região cortada pela ferrovia, juntou-se ao assinalado preconceito contra os trabalhadores nacionais. Em 1907 esperava-se a força de trabalho de 2.000 imigrantes que deveriam trabalhar na linha São Francisco, os quais, suponho, foram desviados para a linha tronco. No início de 1908 os jornais do interior catarinense comemoravam a aproximação das turmas. Festejava-se a possibilidade de colonização via EFSPRG. O papel atribuído ao caboclo morador da região era de contribuir para o progresso, mas não como mão-de-obra, e sim como produtor:

24 O Clarim, Lages, 19/02/1908.

25 Diário da Tarde, Curitiba, 16/04/1908. (Grifos meus).

26 Acredito que parte dos homens trazidos do centro do país era também de imigrantes estrangeiros, descontentes com o trabalho urbano ou expulsos deste mercado. Contudo esta hipótese é de difícil comprovação.

27 MONTEIRO, Duglas Teixeira. Os errantes do novo século: um estudo sobre o surto milenarista do Contestado. São Paulo: Duas Cidades, 1974, p.237. 
Ha muita afluencia de trabalhadores para a estrada de ferro; circula muito dinheiro, os lavradores fazem bastante negocio com mantimentos. Se Deus nos ajudar com uma boa colheita, entrará a opulencia nesta vasta região e o pobre sertanejo que até a presente data apenas vegetava, terá todos os recursos necessarios para um melhoramento material e intelectual. ${ }^{28}$

As referências a imigrantes e migrantes evoluem paulatinamente na documentação durante 1908. Fontes como jornais e relatos memorialísticos de descendentes ou imigrantes atestam o fornecimento de passagens para imigrantes de zonas pobres da Europa para a colonização das zonas contíguas ao caminho de ferro e também para sua construção. ${ }^{29}$ Embora alguns autores acreditem que a colonização no Sul do país abria possibilidades que inviabilizariam a contratação de imigrantes em trabalhos ferroviários, ${ }^{30}$ várias evidências apontam para uma combinação do trabalho agrícola e do povoamento com o trabalho nos caminhos de ferro, durante o século XIX e início do XX.

Tal ocorreu, por exemplo, no Rio Grande do Sul durante o processo de instalação de judeus russos junto a terras da Compagnie Auxilaire de Chemins du Fer au Brésil, tanto na colônia Filipson quanto na colônia de Quatro Irmãos, ambas do início do século XX. Nesta fase, a Compagnie construía o trecho gaúcho da EFSPRG, necessitava de mão-de-obra para explorar a madeira da região e mais tarde veio a utilizar os trabalhos dos colonos na construção do ramal férreo Quatro Irmãos - Erebango. ${ }^{31}$ Observe-se também que a Estrada de Ferro do Paraná contou com os braços de um grande número de italianos, recrutados em algumas colônias mal sucedidas estabelecidas serra abaixo. ${ }^{32}$ No final do século XIX, afirma Holzmann, muitos colonos russos emigrados para o Paraná abandonaram as lides agrícolas para buscar ofícios nas cidades ou então foram construir estradas. ${ }^{33}$ No ramal de Serrinha da EFSPRG, empregaram-se "principalmente italianos e poloneses, além de um pequeno grupo de portugueses e espanhóis". ${ }^{34}$ Um grande volume de poloneses emigrados

28 O Trabalho, Curitibanos, 03/03/1908.

29 Gazeta Catarinense, Florianópolis, 04/04/1908; 08/04/1908. O Trabalho, Curitibanos, 18/04/1908. WANKE, Eno Teodoro. A saga dos imigrantes (de como eles, em busca de felicidade, mudaram de pátria e o que fizeram pelo Brasil). Rio de Janeiro: Edições Plaquette, 1993, p.116.

30 LANNA, Ana Lúcia Duarte. Ferrovias, cidades, trabalhadores (1870-1920). São Paulo, USP, 2002 , p.111. (Arquitetura e Urbanismo, Tese de livre docência em História da Arquitetura).

31 GRITTI, Isabel Rosa. Imigração judaica no Rio Grande do Sul: a Jewish Colonization de Quatro Irmãos. Porto Alegre: Martins Livreiro, 1997, p.37.

32 WANKE, Eno Teodoro. A saga dos imigrantes, p.95.

33 HOLZMANN, Epaminondas. Cinco histórias convergentes. 2 ed. Ponta Grossa: UEPG, 2004, p.48.

34 HELLING, Robert. 40 Jahre im Innern von Brasilien: Erlebnisse eines Eisenbahningenieurs, von Robert Helling. Berlin: Pyramidenverlag, Dr. Schwarz \& Co., [1931], p.28. [Tradução em português de Filipe Neckel, Mirien Plarre e Thiago Benitez. Supervisão: Erica Foerthmann Schultz]. 
dirigiu-se à construção da EFSPRG, especialmente a partir de $1908 .{ }^{35}$ Estudo sobre a história de Ponta Grossa menciona que "A Estrada de Ferro absorveu grande volume de mão-de-obra, inclusive de imigrantes, para sua construção e manutenção". ${ }^{36}$ Acredito que se fosse realizado um levantamento exaustivo destes episódios, se constataria que no Sul do país a mão de obra imigrante foi frequentemente utilizada na construção e manutenção dos caminhos de ferro.

Obras de memórias de imigrantes ou de seus descendentes indicam a arregimentação daqueles para os trabalhos ferroviários. Em certas ocasiões esta se dava ainda na Europa, como no caso dos antepassados (bisavô e avô) de Eno Teodoro Wanke, que foram contratados pela Compagnie Générale de Chemins de Fer Brèsiliens para serviços referentes às "obras de arte" de ferrovias. A propaganda buscava operários especializados, sobretudo junto ao Império Austríaco e na Alemanha, para a construção da Estrada de Ferro do Paraná. ${ }^{37}$ Destacando-se nestas tarefas, tornaram-se altamente especializados, operando em diferentes cargos ao longo da existência. Alguns imigrantes que se dirigiam para a região de Erechim também trabalharam em ferrovias. Stanislau Szynkaruk foi recrutado pouco depois que chegou ao Brasil; Lourenço Trzcinski trabalhou como colocador de dormentes em uma Estrada de Ferro do interior do Rio Grande do Sul e posteriormente foi trabalhar em uma ferrovia paulista. ${ }^{38} \mathrm{Em} 1910$ chegaram a Passo Fundo, interior do Rio Grande do Sul, alguns imigrantes solteiros gravemente enfermos que haviam trabalhado na Madeira - Mamoré e contraído moléstias típicas da região Amazônica. ${ }^{39}$ Buscavam no Sul oportunidade de colonização que não haviam encontrado no Norte do país. Sobre a construção da EFSPRG temos a narrativa de Milton Zomkowski, que relata a chegada de um antepassado ao Paraná e as dificuldades enfrentadas ao início da colonização, minoradas com os trabalhos na ferrovia:

Ele encontrava-se sem dinheiro e sem alimento; entretanto, como havia começado a trabalhar, ajudando colocar dormentes na então importante Estrada de Ferro Paraná - Santa Catarina, as coisas andavam mais favoráveis. ${ }^{40}$

35 GLUCHOWSKI, Kazimierz. Os poloneses no Brasil: subsídios para o problema da colonização polonesa no Brasil. Porto Alegre: Rodycz \& Ordakowski Editores, 2005, p.38.

36 GONÇALVES, Maria Aparecida Cezar e PINTO Elisabete Alves. Ponta Grossa: um século de vida (1823-1923). Ponta Grossa: Kugler Artes Gráficas, 1983, p.119.

37 WANKE, Eno Teodoro. A saga dos imigrantes, p.96 e 103.

38 GARCEZ, Neusa Cidade. Colonização e imigração em Erechim: a saga de famílias polonesas (1900-1950). Erechim: s/ed, 2003, p.61 e 67.

39 GARCEZ, Neusa Cidade. Colonização e imigração em Erechim, p.57.

40 ZOMKOWSKI, Milton. Trajetória de um imigrante. Curitiba: s/ed, 2001, p.9. Algumas fontes, em geral não institucionais nem oficiais, tratam a EFSPRG como Estrada de Ferro Paraná - Santa Catarina. Possivelmente a confusão se explique pela participação posterior desta ferrovia na Rede de Viação Paraná - Santa Catarina. 
Os problemas relacionados à fixação do colono ao solo eram mencionados ainda na documentação oficial, como no caso deste Relatório dirigido ao diretor do Serviço de Povoamento do Paraná:

No primeiro ano do estabelecimento, suporta o imigrante as contrariedades decorrentes do trabalho de aclimação e de adaptação aos usos e costumes do pais para o qual se transferiram [sic] e se a essas contrariedades vem se juntar ao fracasso de sua primeira lavoura, é natural que o desespero the abata o espirito, dando-lhe impetos de abandonar de todo o serviço agricola para dedicar-se a trabalhos mais compensadores de seus esforços. ${ }^{41}$

Desta maneira, muitos imigrantes já fixados à terra saíram de suas colônias visando o ganho de um dinheiro que parecia fácil e certo. Esta prática não era recente e provocava diferentes reações na sociedade paranaense. Embora parte a visse como positiva, já que garantia a subsistência do colono nos tempos de entressafra, outro grupo a abordava negativamente, já que dificultava a fixação definitiva do imigrante. Em 1861 um cronista paranaense assinalava a baixa "qualidade" dos imigrantes europeus, segundo ele quase sempre "viciosos e incorrigiveis". Os poucos lavradores qualificados que adentravam o Paraná acabavam por desertar do trabalho no sertão, transferindo-se para as cidades ou então "vão enganjar-se na qualidade de trabalhadores das estradas de ferro, onde com certeza recebem pingues salarios". ${ }^{42}$ Diferentemente, em 1875 o Presidente da Província do Paraná sugeria que, após a fixação ao solo, o imigrante deveria ser empregado na construção de estradas, cessando assim a alimentação por conta do governo e desonerando os cofres públicos. ${ }^{43}$

Esta alternativa era bastante atraente e acabava por captar europeus de diferentes origens étnicas. No caso da EFSPRG, Wachowic assinalou que "Os trabalhadores eram recrutados nas colônias organizadas por imigrantes nos Estados do Paraná e Santa Catarina”. ${ }^{44}$ Tratando especialmente da presença polonesa nos trabalhos da ferrovia, Tokarski comenta que

quando nos primeiros anos do século $X X$ a construção da Estrada de Ferro São Paulo - Rio Grande e do ramal União da Vitória - São Francisco do Sul invadiu a região do Contestado, não foram poucos os polacos que abandonaram a roça

41 RELATORIO REFERENTE AO ANNO DE 1911 apresentado ao Sr. Dr. Silvino Vicente de Faria, diretor do Serviço de Povoamento, pelo Eng. Manoel Francisco Ferreira Correia. Curitiba: Impressora Paranaense, 1912, p.14.

42 CRUZ, Demétrio Acácio Fernandes da. Introdução aos apontamentos sobre a província do Paraná. In: POLINARI, Marcello. Fontes para a história do Paraná. Cronistas - séculos XIX e XX. Curitiba: Secretaria de Estado da Cultura, 1990, p.26.

43 WACHOWICZ, Ruy Christovam. O comércio da madeira e a atuação da Brazil Railway no sul do Brasil. Boletim do Instituto Histórico, Geográfico e Etnográfico Paranaense, Curitiba, v.XVII, p.43-78, 1984.

44 WACHOWICZ, Ruy Christovam. O comércio da madeira e a atuação da Brazil Railway no sul do Brasil, p.53. 
A construção da Linha Sul da Estrada de Ferro São Paulo - Rio Grande (1908-1910): mão de obra e migrações

e ofereceram mão-de-obra aos trabalhos ferroviários. Era apenas um paliativo aos dissabores encontrados na lavoura..$^{45}$

Os imigrantes poloneses, ao que tudo indica, estavam entre os mais utilizados na construção da ferrovia e na ocupação das colônias da EFSPRG. ${ }^{46} \mathrm{~A}$ partir de 1907 a BRC iniciou forte propaganda na Europa. Várias colônias foram fundadas nesta época para abrigar imigrantes, tanto pelos governos federal e estadual paranaense quanto pela própria EFSPRG. A partir de 1908 “[...] uma parte dos recém-vindos vai trabalhar na construção da ferrovia". ${ }^{47}$ Muitos se direcionaram para a colonização de terrenos contíguos à ferrovia. Gluchowski afirma que ao sul de Ponta Grossa e ao longo da EFSPRG encontra-se o "terreno da colonização polonesa concentrada". ${ }^{48} \mathrm{O}$ grande volume de poloneses imigrados proporcionava mão-de-obra abundante, que em parte ligou-se aos empreendimentos da EFSPRG através das colônias e da construção de sua Linha Sul. No quadro geral, instalaram-se no Paraná 83.012 colonos estrangeiros entre 1829 e 1911, embora muitos não tenham permanecido nas colônias, em parte fracassadas. ${ }^{49}$ No caso das colônias implantadas pela EFSPRG já se contava com a utilização prévia dos imigrantes nos trabalhos de construção da ferrovia.

Para aqueles que não se encontravam nas propriedades da Companhia, havia o esforço dos aliciadores de mão-de-obra que percorriam a região colonial paranaense em busca de braços, a exemplo do que Batista Raphaeli fazia na região serrana. Wanke destaca este recrutamento junto às colônias. ${ }^{50}$ Alguns imigrantes levavam em conta a sazonalidade dos produtos agrícolas, trabalhando em tarefas remuneradas durante a entressafra e retornando à propriedade (onde deixavam a família) no momento das lides do campo. ${ }^{51}$

45 TOKARSKI, Fernando. Os polacos na Guerra do Contestado. In: ESPIG, Márcia Janete e MACHADO, Paulo Pinheiro. (org) A Guerra Santa revisitada: novos estudos sobre o Movimento do Contestado. Florianópolis: Editora da UFSC, 2008, p.259.

46 A BRC planejou a implantação de colônias próprias, contando com a mão-de-obra dos imigrantes envolvidos na construção das ferrovias da Companhia. Em 1908 teve início o serviço de demarcação da primeira área destinada pela empresa para colonização, ocupada em 1909. ESTADO DO PARANÁ, Relatório apresentado ao Presidente do Estado pelo Secretario d'Estado dos Negocios de Obras Publicas e Colonisação, 1910, p.40. Acredito que se trate da Colônia Legru, que a partir de 1910 passou a ser denominada Colônia Nova Galícia. O centro da colônia se encontrava a apenas $37 \mathrm{~km}$ de União da Vitória.

47 GLUCHOWSKI, Kazimierz. Os poloneses no Brasil, p.38. Gluchowski foi cônsul da República da Polônia em Curitiba, tendo publicado a obra que cito originalmente em 1924. Trata-se de interessante fonte de informação sobre o tema.

48 GLUCHOWSKI, Kazimierz. Os poloneses no Brasil, p.72.

49 NADALIN, Sérgio Odilon. Paraná: ocupação do território, população e migrações. Curitiba: Seed, 2001 , p.79.

50 WANKE, Eno Teodoro. A saga dos imigrantes, p.116.

51 Este foi o caso do polonês imigrado Estefano Zoblaski, que deixou a mulher e os filhos menores na colônia de Guarapuava, dirigindo-se à construção da EFSPRG (que, na época, ainda se concentrava na Linha Norte). Contudo não retornou, como esperado, e durante sua ausência contraiu novas núpcias, sendo desmascarado e sofrendo processo. Diário da Tarde, Curitiba, 3/07/1908. 
Este aspecto não escapou ao viajante francês Pierre Denis. Ao tratar da colonização paranaense, afirmou que a abertura da linha São Paulo - Rio Grande representou o fim do período de isolamento das colônias interioranas, que a partir daí tiveram um desenvolvimento impressionante. 0 papel dos colonos na construção também encontra menção: “Durant les longues anneés de la lente construction de la voie, les cólons prirent part aux travaux de la ligne. Ouverte au trafic, elle améliorera efficacement leur condition". ${ }^{52}$

Os trabalhos de construção da EFSPRG afiguravam-se como um meio de ganho alternativo, com o qual se podia contar mesmo em tempos de má colheita. Esta possibilidade era celebrada também por jornais do interior catarinense. No caso da Vanguarda, de Campos Novos, o articulista felicitava a região pela expectativa de colonização trazida pela EFSPRG, sobretudo no Vale do Rio do Peixe. O colono recém chegado teria trabalho remunerador durante a construção da ferrovia, enquanto a família permaneceria nos trabalhos agrícolas. No segundo ano, já poderia vender os produtos; e no terceiro ano, poderia inclusive exportá-los por via férrea. ${ }^{53}$

Todas as estratégias mencionadas acima, utilizadas pela EFSPRG para a obtenção de mão-de-obra, parecem ter alcançado um resultado bastante rápido. A correspondência do chefe de fiscalização do $6^{\circ}$ distrito, engenheiro Alberto Gaston Sengès, ao chefe do Departamento de Fiscalização de Estradas de Ferro, em abril de 1908, assinala um incremento impressionante: "Since January the work has gone on with more activity and the labour has been increased to be further increased to nearly 5.000 workmen within a short time according to information received to me". ${ }^{54}$

Nesta primeira fase da construção temos, portanto, um período inicial de grande estagnação nos trabalhos e uma posterior aceleração, a partir da incorporação da EFSPRG à BRC. Esta dinamização envolveu estratégias de recrutamento de nacionais mas, principalmente, de estrangeiros, quer trazidos de seus países de origem especialmente para a tarefa, quer aliciados nas zonas de colonização, ou mesmo no centro do país. Os estrangeiros recrutados eram basicamente europeus, tendo a BRC desprezado a mão-de-obra japonesa que se oferecia para imigração e colonização em larga escala. ${ }^{55}$ Houve ainda uma

52 "Durante os longos anos da lenta construção da via, os colonos tomaram parte nos trabalhos da linha. Aberta ao tráfego, esta irá melhorar eficazmente sua condição". DENIS, Pierre. Le Brésil au XXe siècle. Paris: Librairie Armand Colin, 1909, p.229.

53 Vanguarda, Campos Novos, 01/06/1908.

54 "Desde janeiro o trabalho ocorreu com maior atividade e a produção foi aumentada com o acréscimo de aproximadamente 5.000 trabalhadores em curto prazo de acordo com as informações que recebi”. SENGÈS, Alberto Gaston. Correspondência a Alberto Gustavo Paulo de Frontin, chefe engenheiro do Departamento de Fiscalização de Estradas de Ferro. Castro, 20 de abril de 1908.

55 Sobre a oferta de imigração japonesa, consultar ESPIG, Márcia Janete. Personagens do Contestado, p.320 e segs. 
transferência irregular de operários de conservação da via permanente dos trechos em funcionamento da EFSPRG e de trabalhadores da linha São Francisco. Porém se a Companhia soube captar grande volume de mão-de-obra com uma rapidez excepcional, encontrou maiores dificuldades em manter tais trabalhadores. As irregularidades no pagamento e a dureza das condições de vida na construção levaram muitos turmeiros a abandonarem os trabalhos. No final da primeira fase da construção, tudo indica que houve uma queda muito expressiva do número de homens engajados no serviço. A administração Stenghel irá reverter este quadro, cumprindo rigidamente a tarefa para a qual fôra contratado.

Uma questão importante refere-se à origem dos turmeiros agregados ao trabalho durante a segunda fase da construção. As referências com as quais conto sugerem que Stenghel prosseguiu com uma política de absorção de mão-de-obra semelhante a que descrevi para a primeira fase, ou seja, estrangeiros diretamente importados para os trabalhos ou aliciados nas colônias paranaenses (prioritariamente) e trabalhadores nacionais da região sul ou do centro do país (secundariamente). A diferença em relação à primeira fase é que os trabalhadores evadiram-se em número muito menor, o que me leva a supor que a reorganização empreendida pelo engenheiro teve de fato resultados positivos. Persiste, portanto, o aliciamento de imigrantes estrangeiros trazidos para a colonização do interior. O jornal curitibano Diário da Tarde, por exemplo, assinala que o recrutamento na Europa deveria ser mais criterioso, pois vinha trazendo "madraços" que abandonavam o núcleo em seguida. ${ }^{56}$

Contudo neste período as referências feitas em periódicos ao recrutamento de trabalhadores para a construção da Linha Sul são mais escassas do que na primeira fase. Em outubro de 1909, noventa operários passaram por Ponta Grossa rumo à construção, não se discriminando, contudo, sua origem. ${ }^{57}$ Cerca de um mês depois, chegaram à mesma cidade, pelo trem do norte, "sessenta trabalhadores hespanhoes e portuguezes, com destino a construcção do sul". ${ }^{58} 0$ jornal $O$ Progresso relata a ocorrência de um "Grande Recrutamento" em Ponta Grossa, em outubro do mesmo ano: "Não sabemos se os que foram recrutados nesta cidade e seguiram com destino áquelle lugar vão pegar em armas ou no cabo das picaretas". ${ }^{59}$

Durante esta segunda fase da construção e durante a administração Stenghel diminuíram as referências na documentação à importação direta de imigrantes para os trabalhos. Acredito que nesta fase ampliou-se a busca por tra-

56 Diário da Tarde, Curitiba, 03/04/1909.

57 O Progresso, Ponta Grossa, 14/09/1909.

58 Diário da Tarde, Curitiba, 08/11/1909.

59 O Progresso, Ponta Grossa, 11/11/1909. 
balhadores nacionais e por estrangeiros já localizados nas colônias existentes. Em 1909 o secretário de Obras Públicas e Colonização queixava-se da falta de critérios na escolha de imigrantes, já que estavam chegando ao estado pessoas não ligadas à lavoragem do solo e que pretendiam apenas aproveitar as vantagens oferecidas pelo serviço de imigração, largando-as logo após em busca de outras atividades. ${ }^{60}$ Durante 1910 assinalou-se uma forte praga de gafanhotos em algumas colônias, além do desconhecimento dos recém-chegados sobre as culturas nacionais: "Devido a esses atrasos a colonia [de São Matheus] nos ultimos annos nada poude exportar, tendo os colonos procurado a subsistencia em trabalhos fóra da mesma". ${ }^{61}$

Em 1911 o Relatório do Serviço de Povoamento do Paraná ressaltava que muitos colonos recém chegados aos núcleos coloniais se retiravam devido à facilidade de colocação em trabalhos de construção de estradas de ferro e em extração de madeiras e erva-mate, pois havia grandes serrarias e barbaquás para beneficiamento inicial da erva-mate instaladas ao longo da Estrada de Ferro São Paulo - Rio Grande. Esta oferecia trabalho remunerador com promessas empolgantes de bons salários, desviando os imigrantes dos núcleos coloniais, onde o trabalho rude da lavoura nos primeiros tempos era menos compensador de seus esforços. Destacava ainda o Relatório que a empresa contava com aliciadores, que deslocavam braços para aqueles serviços. ${ }^{62}$ Foi em novembro daquele ano (1911) que a Southern Brazil Lumber and Colonization Company, subsidiária da BRC, iniciou suas atividades na região, explorando a madeira e desenvolvendo atividades de beneficiamento e exportação de erva-mate. ${ }^{63}$

A terceira fase da construção da Linha Sul da EFSPRG foi marcada pela paulatina diminuição do volume de trabalho e do número de homens em serviço. A partir de fevereiro de 1910 decaíram não apenas o número de turmeiros contratados através dos taifeiros, mas também as horas trabalhadas. Neste período, os trabalhos mais duros, de limpeza do terreno, remoção de terras e abertura de caminhos, já se encontravam feitos. Restavam ainda as chamadas "obras de arte", tais como pontes, bueiros, passagens, túneis, etc., que exigiam uma mão-de-obra mais preparada e experiente.

60 ESTADO DO PARANÁ. Relatório apresentado ao Presidente do Estado pelo Secretario d'Estado dos Negocios de Obras Publicas e Colonisação em 31de dez. de 1909. Curityba: Typ. d' "A Republica", 1910, p.25.

61 ESTADO DO PARANÁ. Relatório apresentado ao Presidente do Estado, 1910, p.25.

62 RELATORIO REFERENTE AO ANNO DE 1912 apresentado ao Sr.Dr. Silvino Vicente de Faria, diretor do Serviço de Povoamento, pelo Eng. Manoel Francisco Ferreira Correia. Curitiba: Oficinas de Artes Gráficas de A. Guimarães \& Filho, s/d., p.5.

63 TOMPOROSKI, Alexandre Assis. O pessoal da Lumber!: Um estudo acerca dos trabalhadores da Southern Brazil Lumber and Colonization Company e sua atuação no planalto norte de Santa Catarina, 1910-1929. Florianópolis, UFSC, 2006, p.18-19. (História, Dissertação de mestrado). 


\section{Os destinos dos turmeiros}

Mas qual foi o destino encontrado pelos milhares de turmeiros que foram sendo dispensados dos trabalhos mais pesados durante o ano de 1910? Algumas fontes nos apontam para caminhos seguidos por estes homens. Sobre este assunto, seria um erro afirmarmos que houve apenas uma destinação, pois havia uma pluralidade de direções possíveis e certamente diferentes escolhas envolvidas. Embora a historiografia afirme que estes homens permaneceram na região, engrossando o caldo social que desembocou no Movimento do Contestado, seria ingenuidade supormos que a opção de todos tenha sido a mesma. Além disso, o descarte dos turmeiros foi paulatina, após janeiro de 1910, e não imediata em um momento preciso.

Possíveis destinos para este contingente humano incluem o deslocamento para o trabalho em outras ferrovias (com destaque para o Ramal São Francisco da EFSPRG, que então necessitava de braços), a simples retirada da região, rumo a novos destinos (possivelmente promovida pela própria empresa, já que estes grupos representavam possíveis posseiros), e a compra ou posse da terra como intrusos na região (sendo esta última uma opção arriscada, devido à ação do Corpo de Segurança da Companhia).

Dentre os milhares de homens dispensados, havia pelo menos uma parte que já tinha direção certa: os imigrantes já localizados que haviam sido aliciados junto às colônias. Estes homens, em sua maioria, haviam deixado terras e plantação, via de regra sob os cuidados de esposa e filhos, para alcançar ganhos razoáveis em um curto espaço de tempo. Seu retorno já era esperado, e em geral estes homens dirigiam-se à colônias (sobretudo paranaenses) cujo acesso era relativamente fácil, através das estradas de ferro e de rodagem. Parece pouco provável que os turmeiros com este perfil tenham permanecido na região do Vale do Rio do Peixe, já que possuíam terras cultivadas e família a sua espera. Infelizmente não conto com uma estimativa numérica para o volume de homens dentre os turmeiros que se encontrava nesta situação, mas acredito (pelas evidências já apresentadas) que se tratava de um grupo nada desprezível. 